\title{
Avaliação Multidisciplinar Cumulativa: um estudo de caso*
}

\section{Cumulative Multidisciplinary Evaluation: a case study}

\section{Maria Helena Viana de Souza' \\ Luiz Síveres ${ }^{2}$}

\footnotetext{
* Texto resultante da Dissertação de Mestrado de título Avaliação Multidisciplinar Cumulativa: análise de uma experiência, defendida no Programa de Pós-Graduação em Educação, área de concentração em Tópicos específicos em Educação, da Universidade Católica de Brasília.

1 Maria Helena Viana de Souza, mestre em Educação (UCB), licenciada em Letras (UFMG) e bacharel em Direito (UniCEUB), especialista em Língua Portuguesa (UniCEUB). Atua na Assessoria Pedagógica (UniCEUB) e participa do Grupo de Pesquisa Profissão Docente e Práxis Educativa (UniCEUB/CNPq). Endereço eletrônico: maria.viana@uniceub.br

2 Luiz Síveres, doutor em Desenvolvimento Sustentável $(\mathrm{UnB})$ e pesquisador na área de formação de professores, vinculado ao Projeto CAPES/PROCAD sob o título A perspectiva psicossocial da formação do professor. Endereço eletrônico: luiz@ucb.br
}

\section{Resumo}

Este artigo se propõe a apresentar um recorte da pesquisa realizada no Centro Universitário de Brasília para conhecer a proposta de Avaliação Multidisciplinar Cumulativa e os desafios enfrentados para sua implantação. Seu objetivo é contribuir para a tomada de decisões dos gestores com vistas à melhoria do projeto pedagógico dos cursos e da formação do discente. A metodologia utilizada foi qualitativa. Alguns documentos institucionais foram analisados e foram feitas 18 entrevistas semiestruturadas. Os dados coletados permitiram concluir que a Avaliação Multidisciplinar Cumulativa já está contribuindo para implementar mudanças na prática avaliativa.

Palavras-chave: Avaliação. Processo decisório. Prática avaliativa.

\begin{abstract}
This paper proposes to show a small part of the research carried out at the Centro de Ensino Universitário de Brasília in order to know the proposal of the Cumulative Multidisciplinary Evaluation and the challenges faced for its implantation. The goal of the paper is to contribute to decision-making by the managers in order to improve the pedagogical project of the courses and the student's formation. The methodology used was qualitative. Some institutional documents were analyzed and eighteen semi structured interviews were made. The collected data allowed to conclude that the Cumulative Multidisciplinary Evaluation is already contributing to implement changes in the evaluation practice.
\end{abstract}

Keywords: Evaluation. Decisive process. Evaluation practice. 


\section{Introdução}

Na década de 1990, o mundo vivia um momento complexo, cercado pelo neoliberalismo e pelas ideologias conservadoras que tentavam reorientar os sistemas educacionais com base na imposição de um pensamento único. O governo federal brasileiro, inspirado em organizações internacionais, iniciou um processo gradual de implementação de um sistema de avaliação do ensino superior. No início dos anos de 1990, surgiu o Programa de Avaliação Institucional das Universidades Brasileiras (PAIUB), desativado em 1995. Foi instituído em 1996 o Exame Nacional de Cursos (ENC), com o objetivo de avaliar os cursos de graduação nos aspectos relacionados ao ensino e à aprendizagem, aplicado aos estudantes concluintes. Foram também incluídos no sistema o Censo de Educação Superior - anual, com indicadores globais sobre as instituições - e a Avaliação das Condições de Ensino (ACE), cujo objetivo era verificar como estavam funcionando os cursos de graduação, em relação à qualificação do corpo docente, à organização didático-pedagógica e às instalações físicas.

O ENC, conhecido como Provão, ainda que boicotado em muitos campi, tornou-se parte da cultura da educação superior no Brasil. Mudanças para o exame foram discutidas e, em 2003, foi formada uma comissão com o objetivo de sugerir alterações ao sistema de avaliação vigente. Em agosto de 2003, a comissão propôs o novo Sistema de Avaliação da Educação Superior - SINAES -, que foi oficialmente instituído por meio da Lei n. 10861 (BRASIL, 2004), aprovada em abril de 2004, quando foi implantada a nova proposta de avaliação da educação superior no Brasil. Segundo Cunha (2005), a avaliação é compreendida como um sistema, numa dinâmica multifacetada, que procura apreender o fenômeno educativo mediante diferentes dimensões. Isso significou que a aferição do rendimento do aluno passou a ser uma das dimensões para julgamento da qualidade das Instituições de Ensino Superior - IES. Este sistema trouxe uma abordagem diferente para o exame de cursos, o Exame Nacional de Desempenho dos Estudantes (ENADE). Este, como o Provão, seria uma ferramenta de avaliação, por meio do diagnóstico de competências e habilidades adquiridas ao longo de três anos de escolarização superior. Este diagnóstico seria, ainda, cruzado com a visão do aluno sobre a sua instituição e com seu conhecimento sobre aspectos mais gerais, não relacionados a conteúdos específicos.
O conceito de avaliação proposto pela Comissão Especial de Avaliação (CEA) procurou consolidar a concepção de avaliação como processo, vinculando a dimensão formativa a um projeto de sociedade pautado pela igualdade e justiça social, fundamentando esse conceito nas ideias de integração e participação. Diante desse contexto, torna-se fundamental a atuação efetiva de todas as instâncias institucionais.

A compreensão desse panorama nos impulsionou a investigar uma proposta do Centro Universitário de Brasília (UniCEUB), ao instituir a Avaliação Multidisciplinar Cumulativa (AMC), aplicada a todos os alunos matriculados nas disciplinas que antecedem os estágios curriculares supervisionados ou profissionais, como mecanismo de melhoria dos resultados acadêmicos dos discentes da educação superior, bem como suas contribuições para promover mudanças nas práticas pedagógicas, para subsidiar decisões dos gestores e para consolidar uma cultura de avaliação.

\section{Quadro teórico}

\subsection{Avaliação institucional}

A partir da criação das escolas modernas, especialmente na França, a avaliação se torna mais estruturada, começa a ter um forte significado político e a produzir efeitos sociais. No Brasil, a partir da década de 1960, segundo Dias Sobrinho (2001), a avaliação recebe metodologias variadas: deixa de ser matéria de especialistas em testes, medidas e currículos, originários da psicologia e passa a receber contribuições de sociólogos, antropólogos, filósofos, administradores e economistas, assumindo um caráter público e político.

A criação do Centro Brasileiro de Pesquisas Educacionais (CBPE), organizado em quatro divisões autônomas responsáveis pela pesquisa educacional, pela pesquisa social, pela documentação e informação pedagógica e pelo aperfeiçoamento do magistério, mostrou que as pesquisas educacionais no Brasil se orientavam segundo as tendências internacionais do pós-guerra, como, por exemplo, na crença do papel da educação como instrumento de formação para a democracia e nas preocupações com o tema das desigualdades educacionais.

Com o Golpe Militar de 1964, a atuação do Instituto Nacional de Estudos e Pesquisas Educacionais Aní- 
sio Teixeira (INEP) ficou restrita ao financiamento da pesquisa e à disseminação de informação educacional.

Na década de 1980, num contexto de reconstrução da democracia no Brasil, observa-se uma tentativa de democratização da educação: as pesquisas feitas em universidades públicas enfatizam os fatores intraescolares, procurando equacionar os fatores sociais e escolares nas desigualdades educacionais. Essas pesquisas, a respeito do rendimento escolar até o início dos anos de 1990, propiciaram discussões em torno do fracasso na escola, refletido em reprovação e repetência na escola de $1^{\circ}$ grau. A relação avaliação-qualidade ganha força no contexto da valorização da educação e, nos mercados nacional e internacional, a avaliação dos sistemas educacionais apresenta-se como uma importante forma de controle (ou de verificação) da qualidade da educação. No Brasil, essa importância está fixada na Lei de Diretrizes e Bases da Educação Nacional, Lei n. 9394/96, que obriga a avaliação dos diferentes níveis do sistema educacional. Essa obrigatoriedade traz em si o pressuposto de que a avaliação pode proporcionar um ensino de melhor qualidade e oferecer dados para que, não só o Estado possa intervir nos sistemas educativos, como também, com a divulgação dos resultados para a sociedade, esta possa estabelecer suas demandas por uma educação de qualidade.

Nesse contexto de avaliação, foi implantado, pelo Ministério da Educação, o Exame Nacional de Cursos (ENC), conhecido como Provão, cujo modelo de avaliação externa estava alicerçado na expectativa de universalização do padrão de qualidade, com a finalidade de avaliar os cursos de graduação das universidades brasileiras.

$\mathrm{O}$ aspecto high stakes (termo técnico na área da avaliação que significa "com consequências significativas para aquele que está sendo avaliado") das avaliações conduzidas pelo INEP, estabelecido oficialmente pelo Decreto n. 3860/01 (BRASIL, 2001), que deveria servir para orientar decisões relativas ao recredenciamento institucional e ao reconhecimento dos cursos, segundo Verhine, Dantas e Soares (2006), nunca foi implementado: somente em alguns casos extremos as instituições perderam o credenciamento e o processo de recredenciamento periódico não chegou a ser posto em prática.

A Medida Provisória 147, publicada no final de 2003, mudou a legislação que regia a avaliação da educação superior. O documento divulgado pelo MEC deta- lhava todos os aspectos da nova abordagem e identificava várias deficiências do Provão, fundamentando conceitos, princípios e características da nova proposta.

A nova proposta de avaliação da educação superior no Brasil, aprovada por meio da Lei n. 10861 de 14 de abril de 2004, apresentou a avaliação como sistema, isto significa a apreensão do fenômeno educativo por intermédio de diferentes dimensões. Ultrapassou, portanto, a lógica da política anterior cuja base de julgamento da qualidade das IES estava centrada na aferição do rendimento do aluno, numa visão parcial e fragmentada da realidade. Na avaliação como sistema, o SINAES considera esta apenas como uma das dimensões de uma dinâmica multifacetada. São, ainda, características da proposta: entender a avaliação numa perspectiva pedagógica, buscando favorecer a qualidade, e promover a melhoria dos processos educativos instituídos. São ideias centrais

[...] as de integração e participação - conceitos fundamentais para a construção de um sistema de avaliação capaz de aprofundar os compromissos e responsabilidades sociais das instituições, bem como promover os valores democráticos, o respeito à diversidade, a busca da autonomia e a afirmação da identidade [...] processo que efetivamente vincule a dimensão formativa a um projeto de sociedade comprometido com a igualdade e a justiça social (INEP, 2007, p. 87).

A proposta do SINAES prevê que a avaliação envolva duas grandes etapas: a autoavaliação ou avaliação interna e a heteroavaliação ou avaliação externa. A autoavaliação articula vários instrumentos e deve ser coordenada pela Comissão Própria de Avaliação (CPA), com ampla participação da comunidade interna, para definição do objeto, dos procedimentos, dos objetivos e dos usos do processo avaliativo, com vistas a compreender e aprofundar os compromissos da IES.

No sistema de avaliação proposto pelo SINAES, pode-se perceber a importância dada à autoavaliação, principal sustentação para garantir ao modelo avaliativo a sua condição pedagógica. Esse foi, e continua sendo, um desafio para cada instituição em particular e para o processo como um todo. Segundo Cunha (2005, p. 206), “[...] no âmbito da comunidade acadêmica, temos teorizado mais sobre a avaliação emancipatória, do que experimentado vivências nesse sentido, pois nossas práticas têm enfatizado, principalmente, traços da avaliação regulatória”.

A avaliação na perspectiva pedagógica emancipatória exige que todas as instituições e todos os membros 
da comunidade educativa - professores, estudantes, funcionários, ex-alunos - se envolvam nos processos avaliativos, juntamente com os representantes do governo, e na análise dos produtos acadêmicos.

Os processos de avaliação são processos culturais e, para avançarmos rumo a uma avaliação institucional emancipatória, são precisos esforços intencionais para consolidar a participação reflexiva e rompermos com “[...] a concepção e a prática da avaliação como mera função regulatória e legalista [...] para isso, devemos partir de outra lógica, com outro sentido filosófico, ético e político" (CUNHA, 2005, p. 208). De pouco adianta melhorar a avaliação se isso não repercute na melhoria das pessoas e do sistema educacional.

\section{Na concepção do SINAES,}

a avaliação de caráter educativo é uma prática social, com objetivos essencialmente formativos, voltada tanto para a obtenção de informações que gerem reflexões indutoras da melhoria da qualidade acadêmica quanto para o julgamento a respeito de como o sistema e as instituições de educação superior cumprem as suas funções públicas (INEP, 2007, p. 92).

Portanto, para alcançar sentido educativo, a avaliação deve ser referendada por um projeto pedagógico assumido coletivamente e que

[...] se instale na escola um clima apoiador ao trabalho pedagógico, baseado na confiança entre os sujeitos, para que se crie a cultura de avaliação formativa em que todos percebam as práticas avaliativas como promotoras das aprendizagens (VILLAS BOAS, 2010, p. 102).

Quando se incorpora a avaliação como cultura, significa que se está assumindo a concepção de conhecimento como processual e provisório e, neste sentido, garantindo a função diagnóstica da avaliação, cujos dados deverão implementar novas ações. É imprescindível uma ética institucional que garanta transparência dos procedimentos e confiança de que os dados não assumirão uma perspectiva punitiva, que coloque as pessoas em estado de insegurança.

Villas Boas apresenta quatro aspectos que articulam a avaliação ao trabalho pedagógico:

[...] o entendimento de que alunos e professores são parceiros na construção do trabalho pedagógico; a necessidade de se planejar a avaliação; o tratamento dado à avaliação nos cursos de formação de profissionais da educação (Pedagogia, licenciaturas e até mesmo em cursos de especialização); e o papel desempenhado pelos exames externos (VILLAS BOAS, 2005, p. 162).

Para a autora, entender o trabalho pedagógico como construção conjunta de professores e alunos trará o entendimento e a prática de avaliação como aliados da aprendizagem, pois se está avaliando não só o desempenho dos alunos, mas o trabalho pedagógico da disciplina e a atuação do professor, o que constitui uma etapa da avaliação interna das instituições.

\section{Avaliação da aprendizagem}

Nas primeiras décadas do século passado, numa visão quantitativa, uma vinculação clássica unia a avaliação a testes, conferindo à avaliação uma identidade instrumental, com base e subsídio à operacionalização de testes. Em meados de 1963, Lee Joseph Cronbach, psicólogo estadunidense, foi o primeiro a vincular as atividades de avaliação ao processo de tomada de decisão: "na linha de tomada de decisão, Cronbach apresenta a ideia de que um teste de aprendizagem deve ser apropriado à decisão a ser tomada e que, para isso, antes de tudo, deve haver definição precisa do propósito do sistema de testagem" (DEPRESBITERIS, 1989, p. 9). Depresbiteris esclarece ainda mais: segundo Cronbach, a avaliação não deveria se prender exclusivamente à mensuração; ela deveria ter por finalidade não apenas fazer um julgamento final, mas também oferecer meios para o aprimoramento dos currículos e a tomada de decisões. Assim, salientando o caráter multidimensional dos resultados da aprendizagem, seria necessária uma coleta diversificada de informações de forma que pudessem ser identificados os elementos que deveriam sofrer intervenção para o aprimoramento das práticas educacionais.

Ainda hoje o pensamento de psicólogos behavioristas influencia o currículo e as práticas de ensino e de avaliação nos sistemas educativos. Nestes sistemas, as aprendizagens complexas não são mais do que o somatório de aprendizagens mais simples e a prática avaliativa é centrada na memorização e nas tarefas rotineiras, pouco interativa e dissociada do ensino e da aprendizagem. Entretanto, segundo Veiga, as investigações no campo das ciências cognitivas

[...] começaram a mostrar que os processos de aprendizagem não seguem propriamente os padrões reguladores. As aprendizagens significativas, as aprendizagens como compreensão, são 
reflexivas, construídas ativamente pelos alunos. Por isso, os alunos não são meros receptores que se limitam a memorizar informações, são sujeitos na construção de suas estruturas de conhecimento (VEIGA, 2008, p. 286).

$\mathrm{O}$ ato do conhecimento e o produto do conhecimento são inseparáveis. Vivenciar a avaliação como prática investigativa para compreender como se dá a aprendizagem dos alunos é um desafio e isto só acontecerá desenvolvendo-se diferentes maneiras de trabalhar os conteúdos do ensino e diferentes formas de avaliá-los. Isso significa que as avaliações devem envolver processos complexos de pensamento e motivar os alunos para vencer desafios e resolver diferentes problemas. É necessário nas avaliações utilizar diferentes procedimentos e instrumentos para coleta de informações e analisá-las de forma sistemática, num processo meta-avaliativo.

Numa perspectiva proativa, a avaliação reúne todas as condições para ser usada em favor da aprendizagem e do desenvolvimento pleno dos alunos em suas múltiplas dimensões - humana, cognitiva, política, ética e filosófica - e não apenas como uma atividade concebida para selecionar, classificar, comparar e excluir. Assim, para Veiga,

ensinar, aprender e pesquisar mediante a inspiração da ética não é transmitir valores morais, mas contribuir para a construção de um novo senso comum ético e solidário. Trata-se de uma ética sociocêntrica e coletiva, decorrente de uma concepção mais ampla de subjetividade (VEIGA, 2004, p. 82).

A avaliação precisa ser, então, uma aliada da aprendizagem de forma que os saberes contribuam para melhorar a qualidade de vida da sociedade. A avaliação, vista numa dimensão política, segundo Gama (1993), pode reproduzir ou transformar.

\section{Função formativa da avaliação}

O ensino superior tem se caracterizado pelo volume de informações que se repassa ao aluno e que "supostamente representa os conteúdos selecionados para garantir densidade teórica aos egressos a fim de que respondam às demandas do mercado de trabalho" (DE SORDI, 2000, p. 232). Muitas vezes, esse volume de informações não é transformado em conhecimentos significativos e, portanto, sobrevive por um curto período. De Sordi manifesta sua inquietação em relação ao ensino superior:
Estaremos formando nossos egressos baseados na busca da competência para agir em situação, ou formando-os para agir em situações artificiais (provas e/ou provões) demonstrarem seus conhecimentos adquiridos, sem maior preocupação com os efeitos educativos de longo alcance de nossa ação didática. [...] não basta ter conhecimentos, a não ser que se saiba como mobilizá-los em situações igualmente complexas, o que sugere habilidades cognitivas de maior profundidade (DE SORDI, 2005, p. 132-133).

Sabemos que é preciso mudar os paradigmas convencionais, buscando-se não só a qualidade para competir e vencer os concorrentes do mercado educacional, mas considerando-se as especificidades dos diferentes projetos pedagógicos. Para isso, é importante que a avaliação não esteja voltada apenas para os resultados numa visão meramente classificatória; a proposta é que se caminhe para uma avaliação formativa, que promova a aprendizagem do aluno, do professor e o desenvolvimento da escola, enfim, uma avaliação "[...] capaz de promover ações que contribuam para a formação das crianças e dos jovens para a cidadania crítica" (VILLAS BOAS, 2008, p. 11). Para implementar essas ações, é imprescindível preparar os professores, não só para que compreendam essas ações, como também para que as incorporem à sua prática. Segundo Mendes (2005),

Avaliação formativa é toda prática de avaliação contínua que pretenda contribuir para melhorar as aprendizagens [...]. Nessa perspectiva, não basta mudar nossa prática avaliativa. Essa nova postura implicará, necessariamente, mudanças na metodologia de trabalho [...]. Isso significa que não basta mudar a forma de avaliar se não mudarmos as formas de organização de nossas aulas. A metodologia precisa ser diversificada, problematizadora e ter como princípio o diálogo (MENDES, 2005, p. 178-183).

No processo de avaliação formativa,

[...] é necessário que o aluno: a) conheça o que se espera dele (objetivos da aprendizagem); b) seja capaz de comparar o seu nível atual de desempenho com o esperado; c) se engaje na ação apropriada que leve ao fechamento da distância entre os níveis (VILLAS BOAS, 2008, p. 41).

Essa autora, repetindo Sadler (1989), esclarece que essas condições são satisfeitas simultaneamente, podendo o próprio aluno gerar a informação necessária ao prosseguimento da sua aprendizagem (automonitoramento) ou essa informação ser de origem externa, portanto associada ao feedback. O automonitoramento e o feedback fazem parte da avaliação formativa e o objetivo do trabalho pe- 
dagógico é, exatamente, promover o desenvolvimento da autonomia intelectual do aluno, ou seja, facilitar a transição do feedback para o automonitoramento.

Essa capacidade para avaliar o próprio trabalho faz parte das aprendizagens a serem adquiridas, não podendo o aluno restringir-se ao julgamento do professor. Essa transição do feedback para o automonitoramento deve ser construído pelo professor e pelo aluno. Nesse processo, segundo Villas Boas (2008, p. 42), “[...] três componentes da avaliação formativa merecem atenção especial: a avaliação informal, a avaliação por colegas e a autoavaliação".

A avaliação informal resulta da observação, dos comentários, dos gestos e dos olhares que podem encorajar ou desencorajar os alunos. A rejeição pode ser praticada em sala de aula e em outros espaços escolares. Quando ela parte dos professores, pode provocar a rejeição também por parte dos colegas. Villas Boas esclarece que:

[...] essa rejeição pode se manifestar de formas diversas: pelo tratamento descortês, negligente ou desinteressado; pela ação de ignorar o aluno e deixá-lo marginalizado na sala de aula; por omissão de orientação para a realização de atividades; pela emissão de apelidos humilhantes; pela comparação entre alunos; pela emissão de comentários públicos sobre a pessoa do aluno; pela emissão de comentários negativos sobre membros de suas famílias etc. (VILLAS BOAS, 2008, p. 44).

A avaliação por colegas, segundo a mesma autora, pode ser o primeiro passo para a autoavaliação, pois os alunos costumam aceitar mais facilmente os comentários de colegas do que de seus professores e, enquanto avaliam as atividades dos colegas, aprendem a avaliar próprio trabalho.

\section{Metodologia}

A pesquisa, no que se refere à sua natureza, privilegiou a abordagem qualitativa que, por seu caráter exploratório, dá conta com maior profundidade das múltiplas características do objeto de estudo. Entre as várias formas que pode assumir uma pesquisa qualitativa, optamos pelo estudo de caso para aprofundar qualitativamente a pesquisa, por estar diretamente relacionado às características que tal tipo de investigação apresenta como adequadas à observação e à análise da realidade de forma natural, complexa e contextualizada. Segundo Good e Hatt (1968), apud Ludke e André,
[...] o caso se destaca por se constituir numa unidade dentro de um sistema mais amplo. $\mathrm{O}$ interesse, portanto, incide naquilo que ele tem de único, de particular, mesmo que posteriormente venham a ficar evidentes certas semelhanças com outros casos ou situações (LUDKE; ANDRÉ, 1999, p. 17).

A pesquisa foi realizada, durante os meses de março e abril de 2012, no UniCEUB -, que adotou a Avaliação Multidisciplinar Cumulativa. Para a coleta de dados, foram feitas 18 entrevistas semiestruturadas e analisados alguns documentos institucionais. Foram entrevistados, após assinatura do Termo de Consentimento Livre e Esclarecido: o diretor acadêmico, responsável pelas questões acadêmicas na Instituição; a coordenadora da Comissão Própria de Avaliação (CPA); a diretora da Faculdade de Ciências da Educação e Saúde; cinco coordenadores de cursos da área de saúde (Biomedicina, Enfermagem, Fisioterapia, Nutrição e Psicologia); um professor e um aluno de cada curso mencionado, indicados pelos coordenadores e que já participaram da Avaliação Multidisciplinar Cumulativa.

A entrevista é uma das principais estratégias para a geração de dados na abordagem qualitativa de pesquisa. As entrevistas tiveram uma duração média de 15 minutos, foram gravadas em áudio e transcritas posteriormente. Foram utilizados roteiros contendo perguntas pré-testadas, que permitiram adaptações no decorrer do trabalho.

Outro procedimento muito importante para o entendimento do objeto da pesquisa foi a análise documental, pois, a partir dela, foi possível fazer inferências. O tratamento dos dados foi realizado a partir de uma análise de conteúdo que visou identificar o que foi dito e sintetizar as informações, de forma que viabilizassem respostas às perguntas da pesquisa. Segundo Bardin (2010), a análise de conteúdo compreende:

[...] um conjunto de técnicas de análise das co-
municações, visando obter, por procedimentos,
sistemáticos e objetivos de descrição do conte-
údo das mensagens, indicadores (quantitativos
ou não) que permitem a inferência de conhe-
cimentos relativos às condições de produção/
recepção (variáveis inferidas) dessas mensagens
(BARDIN, 2010, p. 42).

$\mathrm{Na}$ análise, buscamos correlacionar os estudos dos autores que afirmam a importância da avaliação para a melhoria do processo educativo com a análise dos documentos disponibilizados, a saber: o Estatuto, o Regimen- 
to Geral, a Proposta Pedagógica Institucional, o Plano de Avaliação e a Proposta da Avaliação Multidisciplinar Cumulativa.

\section{A proposta da Avaliação Multidisciplinar Cumulativa: concepção e desafios para im- plantação}

Algumas iniciativas institucionais de avaliação resultam em procedimentos bem-sucedidos, que podem complementar os diagnósticos sobre os cursos de graduação, além dos resultados das avaliações do SINAES. A AMC é uma modalidade que algumas instituições têm utilizado como instrumento especialmente em relação ao processo de ensino-aprendizagem. Na instituição investigada, esse tipo de avaliação foi aplicado, no primeiro semestre de 2008, pelo curso de Direito, com o objetivo de "[...] avaliar o conhecimento, as competências e as habilidades adquiridas pelo discente ao longo do curso, até os semestres anteriores à oferta do estágio curricular supervisionado e ou estágio profissional" (UNICEUB, 2008).

A Diretoria Acadêmica, por entender que essa avaliação multidisciplinar poderia beneficiar os outros cursos e por considerá-la mais um instrumento a ser utilizado para autoavaliação, decidiu implantá-la em 2009 em todos os cursos oferecidos pela instituição, com a finalidade de ser, também, um instrumento de autoavaliação pelo discente. Assim, a CPA, procurando atender às condições de projeto institucional, integrou a AMC ao conjunto de ações do processo de autoavaliação da instituição, alertando para que os resultados alcançados pelos discentes não se tornassem o único indicador de avaliação para diagnóstico do curso e tomada de decisões. A CPA salientou, também, que a AMC não teria a mesma finalidade da avaliação de aprendizagem aplicada nos cursos.

A proposta inicial para realização da AMC aconteceu nos meses de maio e outubro. Posteriormente, passou a ser realizada no mês de outubro, sendo obrigatória para os alunos enquadrados no semestre que antecede o estágio curricular supervisionado ou o estágio profissional e facultativa para os demais alunos. A participação se dá mediante inscrição prévia no Sistema de Gestão Institucional e o resultado é considerado na composição da menção das disciplinas do semestre de obrigatoriedade.
No UniCEUB, cada curso organiza uma prova, com questões interdisciplinares, contextualizadas, dentro da perspectiva dialógica de Bakhtin e segundo a teoria de resposta ao item, com o objetivo de estimular o pensamento reflexivo do aluno para solucionar questões que integram diferentes conteúdos, dentro de um contexto prático, e que requerem o seu posicionamento. A decisão de aplicar a prova, obrigatoriamente, aos alunos que estão cursando as disciplinas que antecedem o estágio é avaliar a própria matriz curricular e verificar se eles desenvolveram as competências elencadas no Projeto Pedagógico do curso.

A responsabilidade pela organização das provas é dos coordenadores dos cursos, com a participação dos professores. Nos cursos, corpus desta pesquisa, cada prova apresenta 32 questões objetivas, que se referem aos conteúdos e aos objetivos dos planos de ensino dos componentes curriculares de cada matriz. A CPA sugere que haja questões de baixa, de média e de alta complexidade.

O somatório das pontuações relativas às questões respondidas corretamente é convertido em menção pela medida estatística de Percentil, que estabelece a posição relativa de um indivíduo em relação ao grupo.

Como incentivo à participação, é disponibilizado ao aluno participante um certificado para ser computado como carga horária complementar, no total de 12 horas. Também são considerados a participação e o desempenho no processo seletivo para monitorias, projetos de extensão, Programa de Iniciação Científica e outras oportunidades em que se concorre à condição de bolsistas.

A AMC constitui uma das etapas de autoavaliação da instituição pesquisada e, por meio de relatórios organizados pela CPA, tendo como referência a tabela de especificação de habilidades e competências (quando previstas no Projeto Pedagógico do curso) ou os conteúdos e as operações mentais a serem aferidas (no caso dos cursos que preveem o ensino por conhecimentos), faz-se o acompanhamento do processo, e as informações contidas nos relatórios podem otimizar ações voltadas ao Projeto Pedagógico dos cursos.

Segundo a CPA, a elaboração de tabela de especificação dos eixos principais do perfil do profissional pode auxiliar os coordenadores a identificar habilidades e competências ainda não demonstradas pelos discentes, bem como permitir a verificação de lacunas nos projetos 
pedagógicos e um melhor entendimento do perfil do profissional que se deseja formar.

A instituição, ao assumir como política a busca de um ensino de qualidade, está investindo na formação continuada de professores, buscando a melhoria dos processos didático-pedagógicos. De Sordi (2000, p. 232) afirma que "[...] a alteração substantiva das práticas de avaliação pode contribuir para que a aprendizagem ganhe significado". Esta "alteração substantiva" acontecerá, realmente, quando a mudança for incorporada à própria prática pedagógica.

Segundo os treze professores entrevistados, isto é: dois diretores, seis coordenadores e cinco professores responsáveis por disciplinas nos cursos de Biomedicina, Enfermagem, Fisioterapia, Nutrição e Psicologia, foram muitas as dificuldades enfrentadas para a implantação da AMC, que podem ser assim categorizadas:

a) Formulação de questões

[...] como elaborar aquelas questões operatórias, a gente teve até oficinas, mas prá gente ainda é um desafio muito grande. (Coordenador de curso)

[...] no começo foi muito difícil desenvolver questões operatórias. (Professor do curso de Fisioterapia)

Para implementar mudanças, é preciso promover cursos para preparar os professores, não só para que compreendam as novas técnicas, mas que as incorporem às suas práticas. A instituição, conforme depoimento dos professores, já está oferecendo oficinas para instrumentalizá-los para elaboração de questões do tipo operatório, no intuito de que as mudanças sejam, gradualmente, incorporadas às práticas.

\section{b) Concepção de processo}

Não basta, então, que o professor elabore questões operatórias para a prova e que "nem sempre trabalhe essas questões na sala de aula" (Coordenador de curso). Para De Sordi,

o professor pode, por meio de sua forma de mediação, construir um trabalho pedagógico altamente eficaz, mas ele próprio terá de romper com a visão de avaliação ainda hegemônica que se orienta pelo eficientismo e valorização do produto em detrimento do processo (DE SORDI, 2005, p. 122).

É necessário, portanto, rever as práticas pedagógicas no decorrer do semestre letivo, conforme podemos perceber nas falas dos gestores:
[...] o processo pedagógico do professor ainda não era totalmente, como ainda não é, totalmente operatório. Então esse foi um dificultador muito grande. (Diretor)

[...] às vezes a questão até é operatória, que o professor elaborou [...] mas nem sempre a aula dele é operatória, teve essa separação. (Coordenador de curso)

A respeito de aulas operatórias, Ronca e Terzi (1991) esclarecem que nelas os alunos argumentam, analisam, elaboram reflexões e os professores estimulam os alunos a aprofundarem os conhecimentos ali construídos.

\section{c) Execução da proposta}

Para operacionalização da AMC, algumas ações precisaram ser desencadeadas, principalmente no período de implantação, quando era necessária a sensibilização dos corpos docente e discente, além de esclarecimentos relativos à análise dos dados e à possibilidade de estes dados subsidiarem a gestão do Projeto Pedagógico do curso.

[...] você tem de ter um grupo de pessoas para pensar, para fazer contato com os coordenadores, para sensibilizar, fazer eventos que possam mostrar o vínculo, inclusive com o PP, como isso volta para o projeto, como você interpreta [...]. (Coordenador de curso)

[...] a gente não tem tempo para sentar com os outros professores [...] montar essa questão juntos (Professor do curso de Fisioterapia)

A proposta é de uma avaliação interdisciplinar, portanto, foi e continua sendo imprescindível esse momento de encontro e discussão para os professores definirem o conteúdo da questão e, depois de aplicada a prova, avaliarem os problemas detectados.

d) Resistência por parte de coordenadores e professores pelo fato de a AMC ter sido imposta:

[...] nós tivemos uma resistência em alguns cursos mais que em outros, dos próprios coordenadores, em relação à implantação, porque ela veio muito de cima para baixo (Diretor)

[...] para mim foi uma imposição [...] não houve, assim, um processo (Professor do curso de Fisioterapia)

De acordo com Gather Thurler (1994), apud Alves e Machado,

a mudança das práticas não se decreta, só nos regimes totalitários a teoria cria os fatos. Neste sentido, é bom relembrar que "a eficácia das escolas não se mede: ela constrói-se, negocia-se, pratica-se e vive-se" (ALVES; MACHADO, 2008, p. 93). 
Para que haja, realmente, adesão ao processo de mudança nas avaliações, é preciso que os professores compreendam os objetivos e as possibilidades de melhoria para o processo de ensino e de aprendizagem. Dessa forma, a prática dialógica, princípio que permeia as relações não só na educação superior, mas em todas as relações sociais, é imprescindível em qualquer processo de mudança. As mudanças, para serem incorporadas às práticas, precisam ser discutidas de forma que a compreensão facilite o processo.

e) Compreensão das questões por parte dos alunos

Durante as aulas, os alunos não estão acostumados a refletir, argumentar e pesquisar, ao se depararem com questões que exigem raciocínio e não, simplesmente, a memória, certamente encontram dificuldades para respondê-las:

[...] muitos alunos falam assim: a gente sabe que o professor deu essa aula, a gente sabe o conceito, mas não entendi a pergunta, eu não entendi o que ele queria que eu fizesse, ou não sei o que era para explicar. (Coordenador de curso)

Mas se o professor elabora a questão de forma confusa e não diz o que espera que o aluno faça, certamente não obtém as respostas desejadas. A esse respeito, Ronca e Terzi afirmam:

[...] a clareza na proposição do enunciado e o zelo na apresentação de orientações básicas (de como fazer ou de como responder) provocam no aluno um sentimento de confiança. A prova não quer medir o que o aluno não sabe: deve oferecer condições para que o aluno possa mostrar o que sabe e, principalmente, como pensa (RONCA; TERZI, 1991, p. 44).

\section{A Avaliação Multidisciplinar Cumulativa na visão dos alunos}

Procurando conhecer os impactos da implantação da AMC na prática pedagógica e avaliativa, além das possíveis contribuições para a formação do discente, foram entrevistados cinco alunos, um de cada curso (Enfermagem, Nutrição, Biomedicina, Fisioterapia e Psicologia), indicados pelos coordenadores e que já haviam participado de uma edição da AMC. Iniciando a entrevista, foilhes perguntado o significado da AMC:

[...] para mim foi muito legal fazer porque tive uma noção do que tinha aprendido ou não. (Aluno do curso de Psicologia)
[...] uma forma para avaliar o que a gente vem aprendendo [...] se está conseguindo absorver o que foi passado. (Aluno do curso de Nutrição)

A resposta dos alunos confirma que a AMC foi uma oportunidade para realizar a autoavaliação. Segundo Villas Boas (2008), a autoavaliação permite que o aluno registre suas percepções e identifique futuras ações, pois essa habilidade de refletir, analisar e desenvolver as atividades por meio de exame crítico da sua produção constitui um processo metacognitivo que resultará no êxito das aprendizagens. Ainda, a respeito do significado da AMC, os alunos responderam:

[...] uma abordagem multidisciplinar [...] nos dá um maior conhecimento de todas as disciplinas, sendo que estas disciplinas enfocam juntas, assim, o conteúdo de uma matéria com a outra [...] (Aluno do curso de Enfermagem)

[...] avaliação que, a princípio, vai conseguir avaliar todas as áreas de atuação da gente e, às vezes até, uma interdisciplinaridade que eu acho que a gente precisa. (Aluno do curso de Biomedicina)

Esses alunos perceberam, nas questões que abordavam conteúdos de várias disciplinas, numa visão integradora, uma oportunidade para avaliar diferentes áreas de atuação, inclusive ajudando a definir prioridades de formação para as quais iriam optar.

Em seguida, a respeito de serem comentados os resultados da AMC em sala, três alunos afirmaram que não. $\mathrm{O}$ aluno de Fisioterapia afirmou:

Sinceramente, ouvi uma vez um comentário. Mas normalmente as pessoas fazem e não divulgam muito, não analisam as questões depois.

Apenas o aluno de Biomedicina afirmou:

Os resultados muitas vezes são comentados dentro de sala, geralmente as dúvidas até são trazidas pelos alunos e os professores debatem, para esclarecer as dúvidas, geralmente no quadro.

A esse respeito, Villas Boas esclarece: “[...] é necessário que o aluno: a) conheça o que se espera dele (objetivos da aprendizagem); b) seja capaz de comparar o seu nível atual de desempenho com o esperado [...]" (VILLAS BOAS, 2008, p. 41). Portanto os resultados precisam ser comentados e discutidos com os alunos, pois o objetivo do trabalho pedagógico é, como foi dito anteriormente, promover o desenvolvimento da autonomia intelectual do aluno, facilitando a transição do feedback para o automonitoramento.

Os docentes, quando questionados a respeito das contribuições da AMC, afirmaram ter havido mudanças 
nas práticas em sala. Nesse sentido, foi perguntado aos alunos se as avaliações ao longo do curso seguiam a mesma metodologia adotada pela AMC. Algumas respostas confirmaram essa contribuição:

Algumas sim, outras não. Mas no geral a maioria segue. (Aluno do curso de Fisioterapia)

Sim. São questões contextualizadas, englobando vários conhecimentos. (Aluno do curso de Enfermagem)

Sim, de maneira geral seguem: as questões exigem mais reflexão, principalmente se trazem um caso clínico. (Aluno do curso de Biomedicina)

A contextualização nas questões faz com que o aluno deixe de lado a simples memorização, amplie o pensamento para compreender o que foi lido, numa relação leitor-contexto, via texto. Assim, a memorização passa a ser um meio e não um fim em si mesma.

Perguntados se foi importante, para a formação, terem participado da AMC, responderam:

foi importante participar [...] ajuda até saber [...] se nosso conhecimento está bom [...] onde deve ser melhorado. (Aluno do curso de Enfermagem)

[...] considero (importante) prá gente saber como vem sendo o nosso crescimento [...] uma autoavaliação [...] o que a gente precisa rever. (Aluno do curso de Nutrição)

Sim, deu para ter uma base geral do que eu tinha aprendido. (Aluno do curso de Psicologia)

Sim, pois é uma forma de avaliar o conteúdo ao longo dos anos e ver como está o desempenho. (Aluno do curso de Fisioterapia)

As respostas indicam que a AMC, em relação aos alunos, está atingindo o seu objetivo, que é o de permitir uma autoavaliação. É preciso, agora, aumentar a participação dos alunos que estão enquadrados nos semestres que antecedem os estágios e que representam o públicoalvo da avaliação, para atingir o outro objetivo, que é subsidiar o processo decisório dos gestores.

As entrevistas com os professores mostraram que, embora alguns gestores ainda não tenham conseguido utilizar os dados gerados pela AMC, devido à pequena participação dos alunos, a avaliação, como propulsora da qualidade, é propositiva e capaz de estimular mudanças. Conforme depoimento dos diretores e dos coordenadores, a AMC pode subsidiar as decisões na gestão do PPC e pode contribuir na revisão das práticas pedagógicas. buição com a oferta de oficinas para a elaboração de questões do tipo operatório, e estas oficinas contribuíram para operar mudanças nas práticas pedagógicas em sala. Para os alunos, a AMC está sendo considerada uma oportunidade para realizar uma autoavaliação e também trouxe mudanças nas práticas avaliativas em sala, com questões mais contextualizadas e interdisciplinares.

\section{Conclusões}

A proposta de avaliação da educação superior apresentou a avaliação como sistema, envolvendo duas grandes etapas: a autoavaliação ou avaliação interna e a heteroavaliação ou avaliação externa. A autoavaliação institucional articula vários instrumentos e é coordenada pela CPA, com ampla participação da comunidade interna. A avaliação requer dos atores envolvidos compromisso ético, conscientização política e uma prática pedagógica reflexiva, crítica, criativa e inovadora. Segundo Villas Boas (2005), o desafio para as instituições é conciliar o impacto dos exames externos sobre o trabalho pedagógico, isto é, conciliar a avaliação formativa com a somativa, que apela para a competição.

A pesquisa realizada mostrou os desafios e as contribuições da AMC. Segundo os alunos entrevistados, ela possibilita uma autoavaliação, além de ser uma possibilidade para discutir com os colegas posições divergentes e, talvez, até redirecionar as opções profissionais. Dessa forma, o aluno pode rever sua trajetória de aprendizagem e criar suas próprias estratégias de superação.

A pesquisa mostrou, também, que o professor, a partir de sua participação na oficina de questões operatórias, promovida dentro da proposta de formação continuada dos docentes, está refletindo sobre suas práticas avaliativas e buscando revê-las. O sentido da avaliação é compreender a interação entre o que e como se ensina e entre o que e como se aprende, para que se possa promover uma intervenção consciente do professor, refazendo o seu planejamento e seu ensino. Mas a avaliação não deve ser uma tarefa exclusiva dos professores, deve ser partilhada com os alunos e com outros professores. No caso da elaboração de questões para a AMC, que é uma prova com questões interdisciplinares, é imprescindível que os professores se reúnam para discussão das questões e, depois, após a correção, para análise dos resultados. 
As mudanças na prática avaliativa só ocorrerão se houver conscientização de toda a comunidade acadêmica. De acordo com Mendes, "essa é a forma de ampliar o grupo de adesão às novas concepções de avaliação e consequentemente de educação. Só muda quem adquire consciência e desejo de mudança" (MENDES, 2005, p. 188). Para Villas Boas (2008), na avaliação formativa é possível, a partir de evidências das aprendizagens dos estudantes, que os professores ajustem os procedimentos pedagógicos em desenvolvimento e que os alunos ajustem suas estratégias de aprendizagem.

A título de conclusão, embora a AMC seja um instrumento avaliativo aparentemente incompatível com uma avaliação processual, porque acontece num momento estanque, pode contribuir para o processo de ensino e aprendizagem, pois, por meio dela, podemos verificar o desenvolvimento das habilidades intelectuais dos estudantes (raciocínio lógico, capacidade de estabelecer relações entre os diferentes conteúdos, capacidade de aplicação de conhecimentos etc.), sendo, também, um instrumento que permite otimizar ações voltadas ao projeto pedagógico dos cursos e à prática pedagógica dos docentes, além de permitir ao discente a autoavaliação. Ressaltamos, ainda, a importância, além da realização da prova, do tratamento a ser dispensado aos resultados proporcionados pelo instrumento, pois "[...] mudar a realidade detectada é que nos torna bons avaliadores" (MENDES, 2005, p. 191).

\section{Referências}

ALVES, Maria P.; MACHADO, Eusébio A. Avaliação com sentido(s): contributos e questionamentos. Portugal: De Facto Editores, 2008.

BARDIN, Laurence. Análise de conteúdo. Lisboa: Edições 70, 2010.

BRASIL. Lei n. 10861, de 14 de abril de 2004. Institui o Sistema Nacional de Avaliação da Educação Superior - SINAES e dá outras providências. Brasília, DF, 2004. Disponível em: <http://portal.mec.gov.br/arquivos/ pdf/10861.pdf>. Acesso em: 5 out. 2011.

BRASIL. Decreto no 3860, de 9 de julho de 2001. Dispõe sobre a organização do ensino superior, a avaliação de cursos e instituições e dá outras providências. Diário Oficial [da] República Federativa do Brasil. Brasília, DF, 10 julho, 2001. Disponível em: < http://portal.mec.gov.br/sesu/arquivos/ pdf/DecN3860.pdf>. Acesso em: 5 out. 2011.
BRASIL. Ministério da Saúde. Resolução CNS nº 196, de 10 de outubro de 1996. Aprova diretrizes e normas regulamentadoras de pesquisas envolvendo seres humanos. Diário Oficial [da] República Federativa do Brasil. Brasília, 16 de outubro de 1996. Seção 1, p. 21082.

CENTRO UNIVERSITÁRIO DE BRASÍLIA - UniCEUB. Estatuto do Centro Universitário. Brasília: UNICEUB, 2000.

CENTRO UNIVERSITÁRIO DE BRASÍLIA - UniCEUB. Regimento Geral do Centro Universitário de Brasília. Brasília: UniCEUB, 2001.

CENTRO UNIVERSITÁRIO DE BRASÍLIA - UniCEUB. Estatuto Mantenedora. Brasília: UniCEUB, 2003.

CENTRO UNIVERSITÁRIO DE BRASÍLIA - UniCEUB. Projeto de Avaliação Multidisciplinar Cumulativa. Brasília: UniCEUB, 2008.

CENTRO UNIVERSITÁRIO DE BRASÍLIA - UniCEUB. Plano de Autoavaliação. Brasília: UniCEUB, 2009.

CENTRO UNIVERSITÁRIO DE BRASÍLIA - UniCEUB. Proposta Pedagógica Institucional - Referencial norteador da formação de profissionais. Brasília: UniCEUB, 2012.

CUNHA, Maria Isabel de. OSistema Nacional de Avaliação da Educação Superior (SINAES): a autoavaliação como condição emancipatória. In: CUNHA, Maria Isabel de. (Org.) Formatos avaliativos e concepção de docência. Campinas: Autores Associados, 2005. p. 201-213

DEPRESBITERIS, Léa. O desafio da avaliação da aprendizagem: dos fundamentos a uma proposta inovadora. São Paulo: Editora Pedagógica e Universitária, 1989.

DE SORDI, Mara Regina Lemes. Avaliação da aprendizagem universitária em tempos de mudança: a inovação ao alcance do educador comprometido. In: VEIGA, Ilma Passos Alencastro; CASTANHO, Maria Eugênia L. M (Org.). A pedagogia universitária: a aula em foco. Campinas, SP: Papirus, 2000. p. 231-248.

DE SORDI, Mara Regina Lemes. Avaliação universitária: mecanismo de controle, de competição e exclusão ou caminho para a construção da autonomia, a cooperação e a inclusão? In: VEIGA, Ilma Passos Alencastro e NAVES, Marisa Lomônoco de Paula (Org.). Currículo e avaliação na educação superior. Araraquara: Junqueira \& Marin Editora, 2005. p. 121-148.

DIAS SOBRINHO, José. A avaliação: técnica e ética. Avaliação, Revista da Rede de Avaliação Institucional da Educação Superior, Campinas, ano 6, v. 3, n. 21, p. 7-19, set. 2001. 
GAMA, Zacarias J. Avaliação na escola de $2^{\circ}$ grau. Campinas: Papirus Editora, 1993.

GONZÁLEZ REY, Fernando. Pesquisa qualitativa $e$ subjetividade: os processos de construção da informação. São Paulo: Thompson, 2005.

INSTITUTO NACIONAL DE ESTUDOS E PESQUISAS ANISIO TEIXEIRA. SINAES: da concepção à regulamentação. 4. ed. Brasília: Instituto Nacional de Estudos e Pesquisas Educacionais Anísio Teixeira, 2007.

KOSIK, Karel. Didática do concreto. Rio de Janeiro: Paz e Terra, 1976.

LÜDKE, Menga; ANDRÉ, Marli E. A. Pesquisa em educação: abordagens qualitativas. São Paulo: EPU, 1999.

MENDES, Olenir M. Avaliação formativa no ensino superior: reflexões e alternativas possíveis. In: VEIGA, Ilma Passos Alencastro e NAVES, Marisa Lomônoco de Paula (Org.). Currículo e avaliação na educação superior. Araraquara: Junqueira \& Marin Editora, 2005. p. 175-197.

RONCA, Paulo A.C.; TERZI, Cleide do Amaral. A prova operatória. São Paulo: Centro de Estudos Vida e Consciência Editora, 1991.

VEIGA, Ilma Passos Alencastro. Educação básica e educação superior: projeto político-pedagógico. Campinas: Papirus, 2004.
VEIGA, Ilma Passos Alencastro. Organização didática da aula: um projeto colaborativo de ação imediata. In: VEIGA, Ilma Passos Alencastro (Org.) Aula: gênese, dimensões, princípios e práticas. Campinas, SP: Papirus, 2008. p. 267-298.

VERHINE, Robert E.; DANTAS, Lys M. V.; SOARES, José Francisco. Do Provão ao ENADE: uma análise comparativa dos exames nacionais utilizados no Ensino Superior Brasileiro. Ensaio: avaliação e políticas Públicas, v. 14, n. 52, p. 291-310, 2006.

VILLAS BOAS, Benigna Maria de Freitas. Práticas avaliativas no contexto do trabalho pedagógico universitário. In: VEIGA, Ilma Passos Alencastro e NAVES, Marisa Lomônaco de Paula (Org.). Currículo e avaliação na educação superior. Araraquara: Junqueira \& Marin Editora, 2005. p. 149-173.

VILLAS BOAS, Benigna Maria de Freitas. Virando a escola do avesso por meio da avaliação. Campinas, SP: Papirus, 2008.

VILLAS BOAS, Benigna Maria de Freitas. Projeto de intervenção na escola: mantendo as aprendizagens em dia. Campinas, SP: Papirus, 2010.

YIN, Robert K. Estudo de caso: planejamento e métodos. 2. ed. Porto Alegre: Bookman, 2001. 